\title{
The Quadrupole Magnets for the LHC Injection Transfer Lines
}

\author{
I. Chertok, S. Chumakov, I. Churkin, O. Golubenko, V, Mejidzade, S. Mikhailov, $\Lambda$. \\ Steshov, A. Sukhanov, B. Sukhina \\ Budker Institute of Nuclear Physics BINP, 630090 Nowosibitsk, Russia
}

\author{
K.M. Schirm, M. Gicsch, W. Kalbreier , G. Kouba, E. Weisse \\ CERN, SL Division, 1211 Geneva 23, Switzerland
}

\begin{abstract}
Two injection trausfer lines, cach ahout $2.8 \mathrm{~km}$ long, are being built to transfer protons at $450 \mathrm{GeV}$ from the Super Proton Synchitotron (SPS) to the Large Hadron Collider (LHC). A total of 180 quadrupole magnets are required; they are produced in the framework of the contribution of the Russian Federation to the construction of the LHC. 'The classical quadrupoles, boilt from laminated sted cores and copper eoils, liave a core length of $1.4 \mathrm{~m}$, an inseribed diameter of $32 \mathrm{~mm}$ and at strength of $53.5 \mathrm{~T} / \mathrm{m}$ at a current of $530 \mathrm{~A}$. The total weight of one magnet is 1,1 ton. For obtaining the required field quality at the small inscribed diameter, great care in the stamping of the laminations and the assembly of quadrants is necessary. Special instruments have been developed to measure, with a precision of some $\mu \mathrm{ml}$, the variations of the pole gaps over the full length of the magnet and correlate them to the obtained field distribution. The design has been developed in a collaboration between BINP and CERN. Fubrication and the magnetie measurements are done at BINP and should be finished at the end of the yoar 2000 .
\end{abstract}

\section{INTRODUCTION}

The magnet system for the I.HC Injection transfer lines ${ }^{1,2}$ will consist of a large number of recuperated magnets from then closed facilities and of newly constructed metgnets ${ }^{3}$ of three different types. Two of them, the main dipoles MBI and the main quadrupoles MQI have been designed in a collaboration between BINP and CERN and are now Jabricated and measured at BINP Novosibirsk, An evaluation of the total costs of construction and operation comparing super-conducting and classical tcchnology lead to a clear advantage of warm magnets, kceping in mind, that the transfer lines will be used only during short periods per day lo' filling the LHC. Table 1 is summarizing the main parameters of the MQI quadrupole.

\section{JI. DesigN}

The MQI quadrupole is built from foul quadrants made of laminated low-carbon steel sheet of $1 \mathrm{~mm}$ thickness, massive end-plates $(30 \mathrm{~mm})$ and water cooled copper coils. Its ratio of length to hal-aperture is large (87.5). Stiffness is obtained by a welded construction using angular plates of $140 \mathrm{~mm} x$ $140 \mathrm{~mm}$. The coils aro operated electrically and hydraulically in series. One of the basic design aims was a minimization of the physical size of the magnet. It was obtained by extending a good field region $\Delta / \mathrm{Gdz} / \mathrm{G}_{0} \mathrm{~d} / z<2^{*} 10^{3}$ over $\mathrm{x}, \mathrm{y}= \pm 20 \mathrm{~mm}$,

Manuscripl received September 27, 1999
Table 1: MQT main parameters

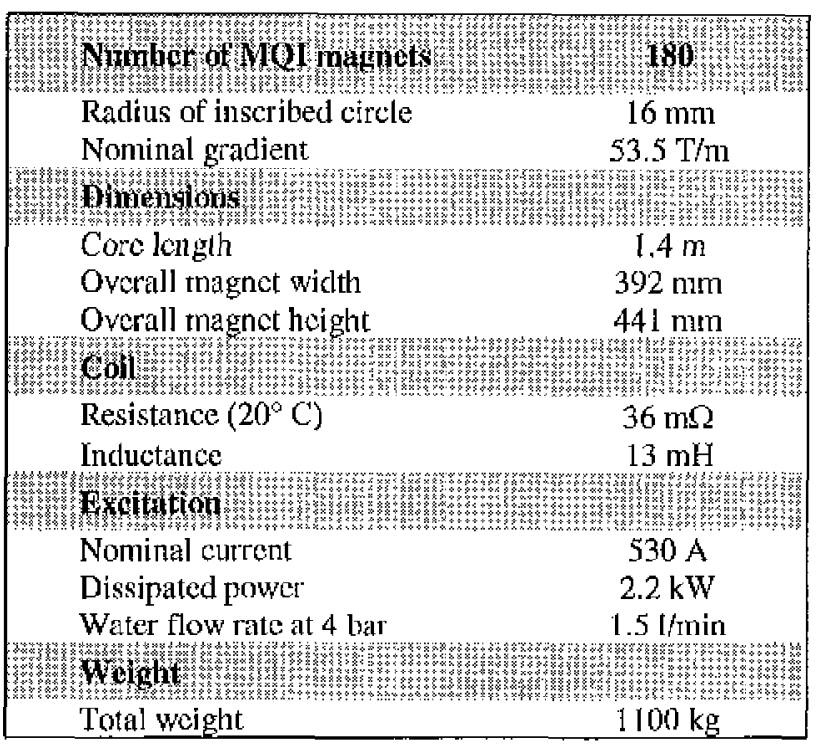

including an area outside the inscribed circle of $16 \mathrm{~mm}$ radius between the poles. Thus, in places where a larget aperture is needed clliptic vacuum chambers will be used.

The pole profile has been chosen such that all influence of end-ficlds on the integral of the gradient is exclusively corrected in the end regions by an optimized end chamfer. The gradient profile inside the magnet will then be flat up-to the limits of the good field region. A different approach would be to include some compensation of end-field effects in the 2-D-profile. This concept was also analyzed, but because of some non-flatness of the gradient profile off-axis at $x>10 \mathrm{~mm}$ it was finally not realized. A plot of the gradient distribution frotn 2-D calculations (MERMAID; OPLRA 2D) for the pole profile chosen is shown in fig. 1.

The pole shape consists of the hyperbolic part, tangent to the hyperbola and then a parallel straight section for the convenience of assembly and control of the assembly precision. For the first order correction of end-fields it chamfer was developed on the pre-serics magnets MQr001 and MQT002 in view of obtain.ing maximum homogeneily of the integrated gradicnt within the specilied good field region. For a simple $45^{\circ}$ lat end chamter the optimum length was reached at around $8.5 \mathrm{~mm}$. 


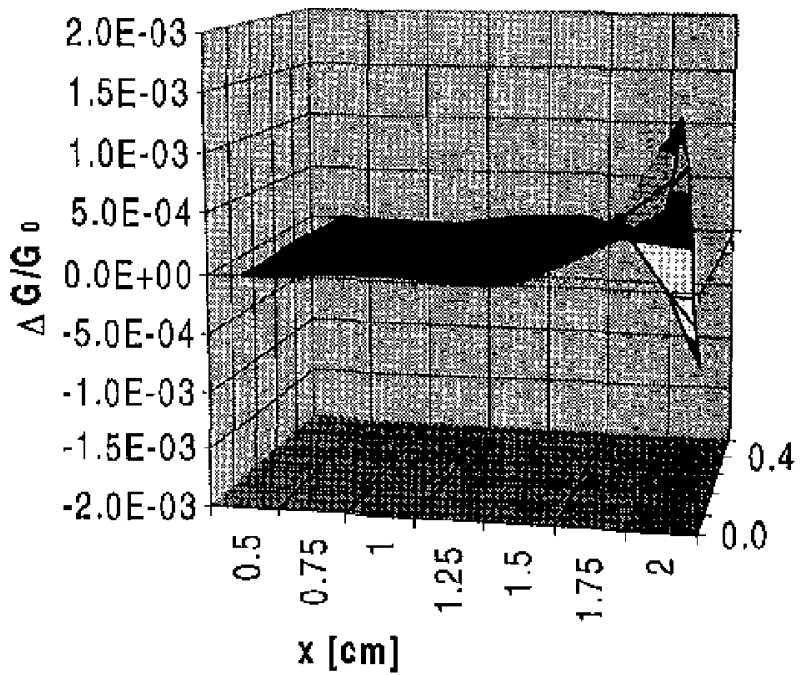

Fig. 1: Flatness of the gradient profile in the $x-y$ plane fiom 2-Dcalculations.

Beam optics calculations of the transficr lines have shown that the sextupole component, i.e. the linear component of the $\Delta \int \mathrm{Gdz}(\mathrm{x})$ distribution, has to be carefully limited for avoiding an emiltance blow-up of the $450 \mathrm{GeV}$ proton beam. Thus the requitements for the integrated gradient distribution were refined as it is shown in Fig.2 by dotted and dashed lines, the "allowance cone". The dashed lines stand for less strict limitations of the field quality at $x_{4} y>10 \mathrm{~mm}$, whereas the field closer to the magnetic center has 10 obcy smaller limits.

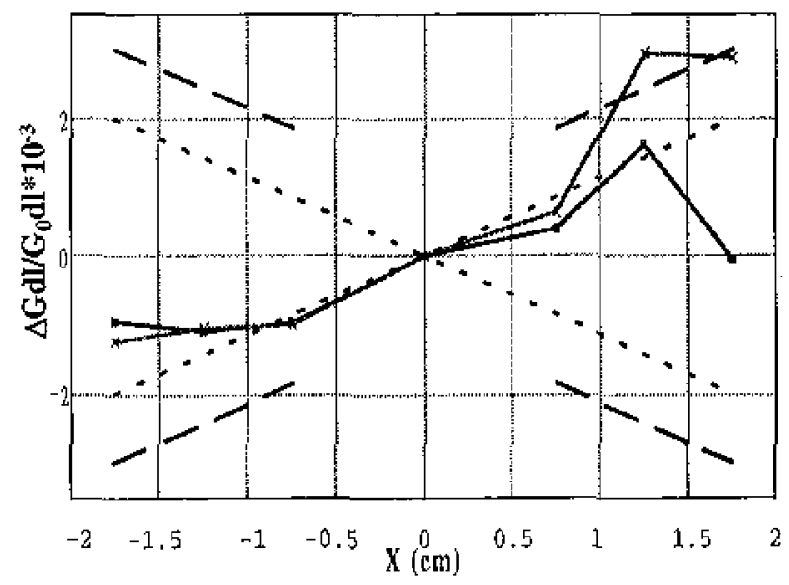

["ig.2: The "allowance cone" for the integrated gradient distribution and mensured curves before $(x)$ and after $(\square)$ end- tip corrections at nominal currejt $(\$ 30 \mathrm{~A})$.

\section{DETAILS OF THE PRODUCTION}

\section{A. Coil production}

The MQI coils consist of 11 turns of high-purity (\$99.95\%) OF copper (Outokumpu) bars of $10.5 \mathrm{~mm} \times 10.5$ $\mathrm{mm}$ scction including a central cooling channel of $6 \mathrm{~mm}$ diameter. The turn-to-turn insulation by glass-fiber tape of $0.15 \mathrm{~mm}$ is applied in two layers, the ground insulation has $1.5 \mathrm{~mm}$ thickness. Assembled coils are impregnated with an cpoxy compound under 3 har pressure. Every coil has to be tested after 6 hours in water with a voltage up-to $4 \mathrm{kV} \mathrm{AC}$ and $2.5 \mathrm{kV}$ DC in successive cycles.

\section{B. Quadrants}

The magnetic properties of the stecl laminations are specified by minimum valucs of the induction $\mathrm{B}(\mathrm{H})$ like: $\mathrm{B}(500 \mathrm{~A} / \mathrm{m})) \geq 1.38 \mathrm{~T} ; \quad \mathrm{B}(1000 \mathrm{~N} / \mathrm{n}) \geq 1.5 \mathrm{~T}$ and $\mathrm{B}(10000$ $\Lambda / m) \geq 1.81 \mathrm{~T}$. All laminations for one magnet are stamped from the same roll of steel shcet. The steel sheet of $1 \mathrm{~mm}$ thickness and a surface insulation by blue steaming is provided by the Verkh-Isetsky Metallurgical Plant (Ekaterinburg; Russia), the stamping of laminations is subcontracted to ZVI (Moscow; Russia). The chemical analysis and measurements of the induction are performed by the stee! supplicr. Control measurements of magnetic properties are done at ZVI and on a CERN permeameter sct-up ${ }^{4}$ in $5 t$. Petersburg, where steel shoct from the same production (the initial rolls have been divided $1 / 3: 2 / 3$ between $\mathrm{MQI}$ and $\mathrm{MBI}$ steel) is used for the MIBI magnet half-core production. Every quadrant is assembled from about 1350 laminations of $1 \mathrm{~mm}$ thickness whilst keeping the total weight within $\pm 0.1 \%$. The stacking factor is exceeding 0.98. Before assembly the latninations are mixed carefully at BINP for distributing the spread in the magnetic behavior equally over the four quadrants. Two solid end-plates of $30 \mathrm{nmm}$ thickness, machined to a precision of $50 \mu \mathrm{m}$ and equipped with temovable end-tips (16 mm), are included in each quadrant. The angular plates are finally fixed by argon arc welding.

\section{Assembly}

Assembled quadrants are equipped with coils and fixed on a solid assembly frame under use of spacers in the pole gaps. The whole construction is then, after alignment including some pre-stress, fixed by welding on the tie-plates along the sides in a specific welding socuence, Coil ends are brazed on afterwards. The sag after assembly is less than $0.2 \mathrm{~mm}$, twist $<1$ mrad. After some leakage and insulation tests of the coils the spacers can be removed from the gaps and the magnel is ready for geometry and magnetic field measurenients. 


\section{Production schedule}

The initial production rate of five magnets per month, after construction and evaluation of the two pre-series MQI, has been realized without major difficulties. All tooling is now ready to increase the rate to the full production speed of 10 units per month. $A$ s almost half of the coils are produced and tested by September 1999 alteady, it scems realistic to expect the termination of the fabrication in December 2000 , as it was initially scheduled.

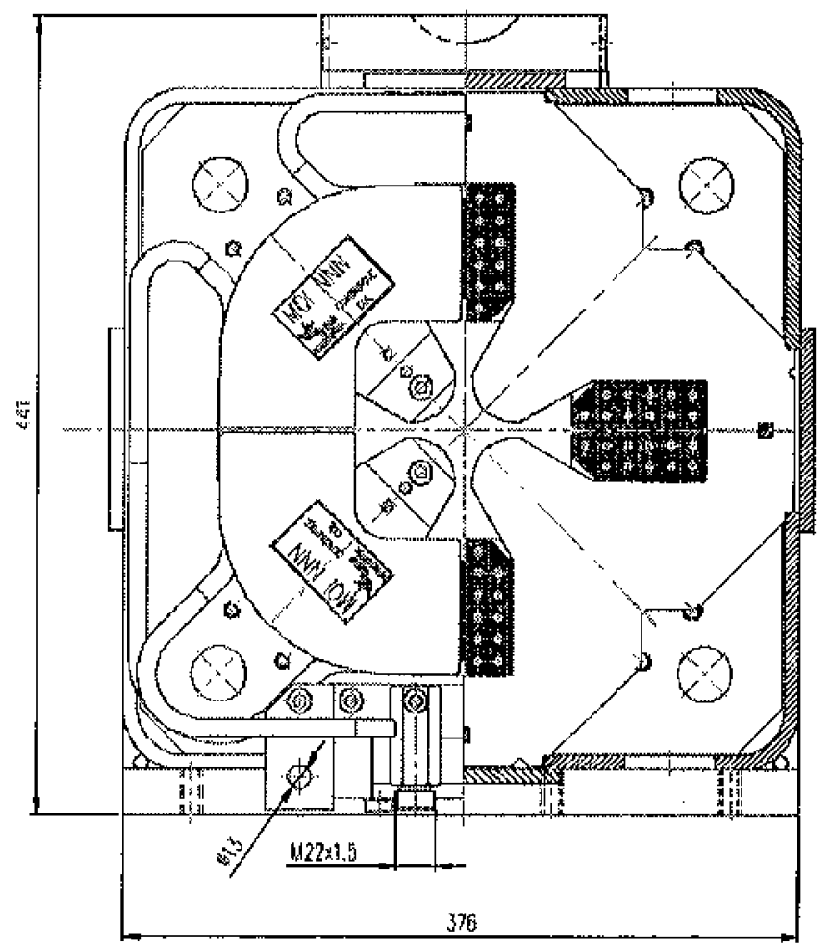

Fig. 3: MQl front view with section.

\section{MaGNITTIC AND MECHANICAL MEAsurements}

\section{A. Mechanical measurements}

The precision of the asscmbly of the four quadrants is controlled by an instrument, shown in fig. 4 , for measuring the four pole gaps $\mathrm{Gl}$ - G4 in one cycle. It has been developed at CERN and produced in industry. Its body consists of three de-coupled $\left( \pm 2^{\circ}\right)$ cylindrical parts, a guiding header plus vertical and horizontal sensor borlies. The measurement is based on four patrs of pins. They translate any deviation from the nominal gap of $9.18 \mathrm{~mm}$ as calibrated in a reference block into an angular move. red into the inductive transducers. Readout of the four anatog channels (tilt measurement via inclinometers is au option) and the position as derived from the driving rope in $1 \mathrm{~mm}$ steps are displayed on a laptop computel using N ${ }^{\text {TM }}$ LabView software. The resolution is better than five microns.

We have compared gap height measurements obtained by this instrument to curves from a sensor integraled in the magnetic measurement bench (1 gap per cycle), devcloped by BINP, and we observe exactly the same mechanical profile with about the same resolution.

\section{B. Magnetic measurements}

All magnets are measured at $530 \mathrm{~A}$ DC corresponding to the nominal gradient of $53.5 \mathrm{~T} / \mathrm{m}$. In addition, measurcments at other ficld levels are done selectively. We use an array of 8 Hall probes lined up at an cqual distance of $5 \mathrm{~mm}$ on an aluminum carriage perpendicular to the magnetic axis. The spacing is measured with 5-7 $\mu \mathrm{m}$ accuracy. The Hall probes arc calibrated ws. NMR probes and have a long term accuracy within $2 \times 10^{-4}$ over the range of $0.5-2 \mathrm{~T}$. Vertical mapping is obtained by $90^{\circ}$ rotation of the sledge. The Hall probe array is moved along the magnet axis in one cycle by means of a drive mechanism including a stepping motor, reducer and high accuracy $1.2 \mathrm{~m}$ long serew. The probe positioning along the axis is precise within $0.1 \mathrm{~mm}$. For one gradient profile each MQI magnet is measured two times. In the first eycle the Hall probe array is displaced in the middle plane by 2.5 $\mathrm{mm}$ in one direction, perpendicular to the magnetic axis, in the second by the same distance in opposite direction. This way, every measurement position is covered by two different probes, and it is possible to eliminate individual features of each Hall probe (temperature drift, speed of aging, clifferent calibration curve ete.). The accuracy of the ficld measurement and the probe spacing atlow us to calculate the integral gradient distribution (absolute) with a cotal accuracy of $\pm 1 \times 10^{3}$.

\section{RESULTS AND CORRELATION OF THE MEASUREMENTS}

The relation between mechanical tolerances in the fabrication and the magnetic field profile obtained is a key issue in the MQI production. It was therefore interesting to find out how much information could be obtained from the simple and fast mechanical tracing of the pole gaps. The $z$ resolved measurements of the lirst two pre-serics magnets MQI00L/002 have been evaluated in this respect and we obtained a good cortelation of mechanics versus magnetic field in the inner region $z=30-110 \mathrm{~cm}$. Afler the correction of some measurement offset a corrclation factor $\mu \sim 9 \mu \mathrm{m} /$ $10^{-3}$ in $\Delta G / G$ was determined for the best fit. A very similar factor was obtained also by $2 \mathrm{D}$ calculations. Thus even very small variations of the gap of the order of ten microns result in significant variations of the gradient in the order of $10^{-3}$ in the regions outside the inscribed diameter where the sensitivity is a maximum.

In the serics production, however, we have to cope with additional parameters like a larger spread in the magnetic properties of the laminations duc to much bigger melts, leading eventually to small magnetic differences in the quadrants at constant stacking factor. This effect is field dependant and tesults in an additional sextupole component as the poles are saturating. A modified steel mixing based on the results of the steel accoptance measurements is now applied systematically. It tutned out in the series prodzction that the mechanical assembly variations ate too big for respecting the magnclic tolctances without a local trimming of the integrated gradient. $\Lambda \mathrm{s}$ the measured curves in fig. 2 indicatc, the MQI magnet needs individual cortection in 


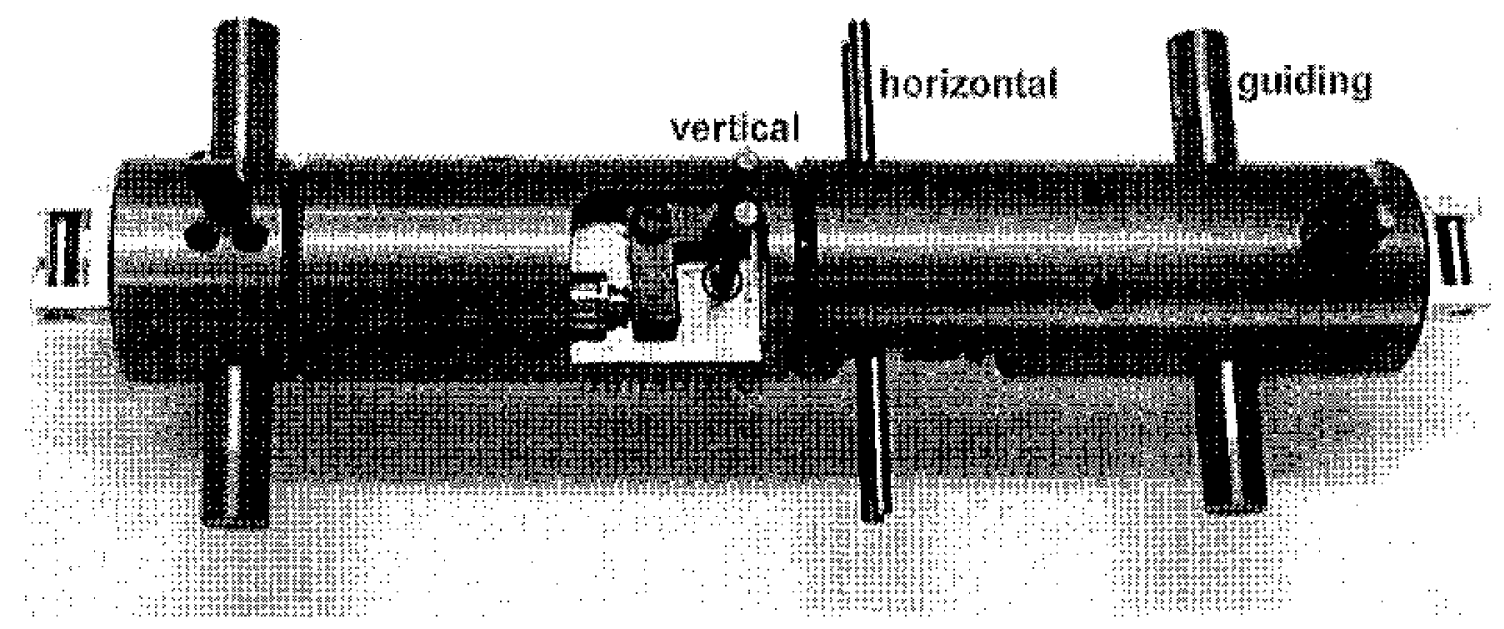

Fig. 4: Mechanical measurcment of four pole gaps simultanconsly.

addition to the $45^{\circ}$ flat chamfer for meeting these reguirements. Therefore all MQI magnets have been brought to specifications after the first magnetic measurement by individually correcting the pole tips. This cortection method has been developed on the basis of 3D calculations. To adjust the profite of the integral gradient, an additional $59^{\circ}$ flat cut on the end tip while simultancously slightly varying the chamfer length is best suited. The geonetry of the cut is shown in Fig.5. This linear cotrection reduces the value of $\int \mathrm{Gdz}$ in the concerned gap while practically not affecting the gradient distribution in the other three gaps.

\section{CONCLUSIONS}

The MQI quadrupole magnet production is wel] under way with more than talf of the coils already produced and successfully lested. Two pro-scries magncts have been constructed and intensively cvaluated in view of the mechanical and magnetic tolerances. Another 10 magnets have been measured before a clear view concening the pole profile, assembly tolerances and the end-tips machining was obtatned. All 27 magnets produced by now fulfill the specifications. But it seems not possible so far to avoid individual end-shim corrections and the related additional magnetic measurements. Nevertheless, the project is advancing well and the MQI production should be terminated at the end of year 2000 .

\section{ACKNOWLEDGMENT"}

We thank H. Grahucr, P, Dallen from CERN and Polycontrol - $\mathrm{CH}^{-}$ 2572 Morigen, Swalzerland tor the development of the instament for gap height mensurements.

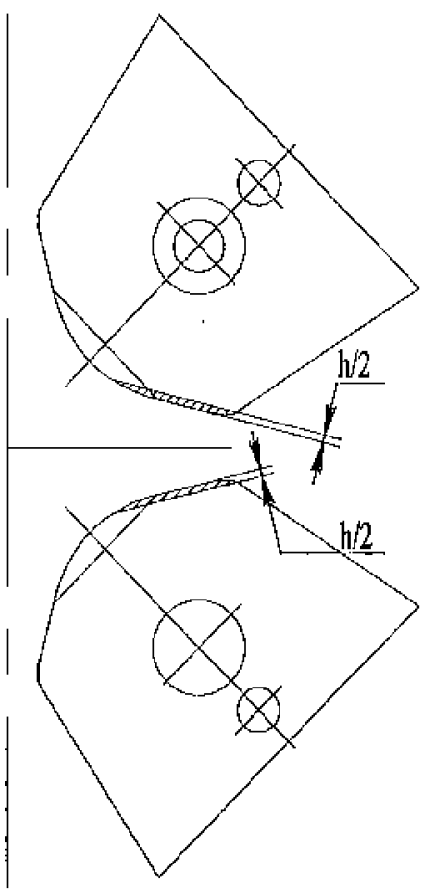

Fig.5: Individual correction of the integrated gradient by a $59^{\circ}$ symuluetric cut of width h, $15 \mathrm{~mm}$ dece, in the end tips on both sides of the magnet.

\section{REFERENCES}

[1] The LALC study group, "The Large Hadron Collider Conceptual Design"; CERN/AC $95-05$ (LHC) 1995

[2] A. Hilaire, V. Mertens and To. Weisse: "Beam Transfer to and Injection into LI IC"; LltC Project Report 208

[3] A llidaire, V. Metens and F. Weisse; "The Magnet System of the LHC Injection T'ransfer I. ines TI2 and TI 8 "; LHC Project Note 128

[4] K.N. Hentichsen; Proc, MT2, Oxford 1967; 0.735 